\title{
Retrospective analysis of malpositioned mandibular third molars in elderly patients
}

\author{
1Anyanechi C. E. BDS, FWACS, FICS. \\ 2 Saheeb B. D. BDS, FDSRCS, FWACS, FICS. \\ 1 Dept. of Oral and Maxillofacial Surgery, University of Calabar/University of Calabar Teaching Hospital, Calabar, \\ Nigeria. E-mail: ceanyanechi@gmail.com \\ 2 Department of Oral and Maxillofacial Surgery, University of Benin/University of Benin Teaching Hospital, Benin-City, \\ Nigeria.E-mail: dauda2000@yahoo.com
}

\begin{abstract}
Objective: To determine the frequency of symptomatic malpositioned mandibular third molars in elderly patients.

Methods: An analytic study of hospital records of elderly patients with symptomatic impacted mandibular third molars over 17 years was undertaken. Information on demographics, types of impaction, reasons for surgical extraction, and complications after treatment were obtained. Those who were asymptomatic would be excluded from analysis.

Results: Altogether, 6214 impacted mandibular third molars were isolated in 5, 431 patients. However, 436 (7.0\%) symptomatic impacted teeth were recorded in 436 (8.0\%) patients and these were extracted, while the rest, 5778 (93.0\%) were asymptomatic. Males were greater than females in the ratio of 1.1:1. The frequency of occurrence of mesio-angular and vertical impactions were significant $(P=0.001)$ compared with disto-angular and horizontal. Periodontal disease was $211(48.4 \%)$ of the case in addition to dental caries and its clinical sequelae 203 (46.6\%) were significant reasons for extractions ( $\mathrm{P}=0.000)$. The common postoperative complications were alveolar osteitis and hypersensitivity of the adjacent molar 22(68.7\%) which related to surgical extraction of disto-angular impactions ( $P=0.001)$.

Conclusion: This study showed the older the patient the less likely malpositioned mandibular third molar suggesting that majority of such impactions do not cause pathology after many years of their presence in the oral cavity. Prophylactic extraction of malpositioned mandibular third molars in all patients should be discouraged, but each case should be treated on merit or when symptomatic.
\end{abstract}

\section{KEYWORDS}

Mandible; third molar; impaction; symptomatic; older patient.

\section{INTRODUCTION}

According to the World Health Organization and United Nations definition, an old patient is a person above the age of 60 years. ${ }^{(1,2)}$ Although impacted mandibular third molars can remain symptomless throughout life, they may be responsible for significant pathology in later life in some individuals, particularly at old age. ${ }^{(3,4,5)}$ Review of available literatures reveals that symptomatic malpositioned mandibular third molars requiring extractions in elderly people are not a common practice in oral and maxillofacial surgery unlike in young adults. $(6,7,8)$ This may not be true as untreated dental diseases can be the origins of other health problem in such patients, including those patients suffer from oral health disorders as a result of ageing process, debilitating disease, handicap or financial difficulty and ignorance. $^{(9,10,11)}$ It has been observed that some physicians and other medical practitioners overlook the condition of teeth and gingiva when investigating health status in elderly patients, even though prolonged inflammation in the oral cavity can contribute significantly to develop diseases in the heart and other organs of the body. (12, 13, 14) Furthermore, loss of teeth may even be related to depression in elderly people. ${ }^{(15)}$

Consequently, the health of elderly people is sometimes complicated by social, economic and psychological factors. These contribute to high morbidity when compared with younger adults. (16) These prevailing factors coupled with the few dental benefits provided by government and nongovernmental organizations for the aged patients in the study community leave many older subjects at risk. This risk includes ignoring common clinical dental diseases that will require simple, non-invasive treatment until there is no alternative but extraction of the offending tooth. This extraction sometimes leaves the patient with adverse post-operative clinical sequelae.

It has been stated by some researchers that the third molar whether impacted or not, plays no 
significant role in the mouth except in disease process and therefore it will be recommended for extraction even in the absence of any pathology relating to them. $(17,18)$ This practice is contentious among investigators and clinicians in dental surgery across the globe, as there is no consensus agreement in this regard. ${ }^{(19,20,}$ ${ }^{21)}$ No study has been done in the past to determine the burden of symptomatic malpositioned mandibular third molars among elderly patients as the prophylactic extraction is not a common practice in this community. The purpose of this study is to determine the frequency of symptomatic malpositioned mandibular third molars in elderly subjects, types of impaction, and reasons for their extraction, including the demographic characteristics of the patients in a tertiary health facility located in the South region of Nigeria.

\section{METHODS}

A retrospective analysis of the medical records of elderly patients with symptomatic and asymptomatic impacted mandibular third molars, who had been attended to Clinic of Oral and Maxillofacial Surgery in the University of Calabar Teaching Hospital in South region of Nigeria since March 2000 till February 2017. Patients older than 60 years of age and have complete clinical and radiological data were studied, while those patients 60 years old and below and those having insufficient data were excluded from the study. Asymptomatic impacted third molars were excluded from analysis. The study was provided a waiver from ethical clearance by the Regional Ethics
Committee of the institution because it was retrospective in design.

Selection of impacted third molar was based on clinical and radiological findings. Information on demographics, type of impaction, reason for surgical extraction and complication(s) were obtained for each symptomatic case. The collected data were analyzed with EPI INFO 7, 0.2.0, 2012 version software (CDC, Atlanta, GA, USA), while simple frequency charts, descriptive statistics and chi-squared test of independence at $95 \%$ confidence level were used, $p$ value of less than 0.05 was considered to be significant.

\section{RESULTS}

Altogether, 6214 impacted third molars were isolated in the 5, 431 patients during the study period. However, $436(7.0 \%)$ were symptomatic in 436 $(8.0 \%)$ patients, and these were treated and included in the study, while the rest 5778 (93.0\%) were asymptomatic. All symptomatic cases met the inclusion criteria. In addition, 429 (98.4\%) of the symptomatic impacted teeth erupted partially into the oral cavity while $7(1.6 \%)$ did not and therefore, invisible in the oral cavity; their diagnosis was made by radiological examination.

Patients' age ranged from 62 to 86 years with a mean age of $65.4 \pm 3.7$ years. The distribution of patients' age and gender are shown in table 1 .

Table (1):

Distribution of patients' age and gender.

\begin{tabular}{|c|c|c|c|c|c|c|}
\hline \multicolumn{4}{|c|}{ Gender } & & & \\
\hline \multicolumn{2}{|c|}{ Male } & \multicolumn{2}{|c|}{ Female } & \multicolumn{3}{|c|}{ Total } \\
\hline Age(years) & $\mathbf{n}$ & $\%$ & $\mathbf{n}$ & $\%$ & n & $\%$ \\
\hline $61-70$ & 93 & 21.3 & 87 & 20.0 & 180 & 41.3 \\
\hline $71-80$ & 82 & 18.8 & 89 & 20.4 & 171 & 39.2 \\
\hline 81-90 & 55 & 12.6 & 30 & 6.9 & 85 & 19.5 \\
\hline Total & 230 & 52.7 & 206 & 47.3 & 436 & 100.0 \\
\hline
\end{tabular}


The frequency of the older patients decreased as the years increased. There were more males than females with male to female ratio of 1.1:1. Majority of the patients, $351(80.5 \%)$ were within the age range of 61 to 80 years. The distribution of patients' age according to the type of impaction and reasons for extraction is shown in table 2.

Table (2):

Patients' age according to types of impaction and reasons for extraction.

\begin{tabular}{|c|c|c|c|c|c|c|c|c|c|}
\hline \multirow{2}{*}{$\begin{array}{l}\text { Age in } \\
\text { years }\end{array}$} & \multicolumn{2}{|c|}{ Patients } & \multicolumn{4}{|c|}{ Types of impaction } & \multicolumn{3}{|c|}{ Reasons for extraction } \\
\hline & $\mathbf{N}$ & $\%$ & MA & Vertical & $\mathbf{D A}$ & Horizontal & $\begin{array}{l}\text { Perio- } \\
\text { dontal }\end{array}$ & Caries & $\begin{array}{l}\text { Perico- } \\
\text { ronitis }\end{array}$ \\
\hline 61-70 & 180 & 41.3 & 93 & 83 & 4 & $\mathbf{0}$ & 72 & 101 & 7 \\
\hline $71-80$ & 171 & 39.2 & 98 & 64 & 4 & 5 & 114 & 55 & 2 \\
\hline 81-90 & 85 & 19.5 & 37 & 9 & 25 & 14 & 25 & 47 & 13 \\
\hline Total & 436 & 100.0 & $\begin{array}{c}228 \\
* 0.001\end{array}$ & $\begin{array}{c}156 \\
* 0.001\end{array}$ & 33 & 19 & $\begin{array}{c}211 \\
* 0.000\end{array}$ & $\begin{array}{c}203 \\
* 0.000\end{array}$ & 22 \\
\hline
\end{tabular}

$\mathrm{NB}: \mathrm{MA}=$ Mesio-angular, DA= Disto-angular, ${ }^{*}$ Significant value

The types of impaction encountered were mesio-angular (52.3\%), vertical (35.8\%), disto-angular (7.6\%) and horizontal (4.3\%) whereas periodontal disease $(48.4 \%)$, caries and its sequelae $(46.6 \%)$ and pericoronitis $(5.0 \%)$ were the reasons for the extractions. The frequency of occurrence of mesio-angular and vertical impactions were significant $(\mathrm{P}=0.001)$ relative to disto-angular and horizontal types (table 2$)$. Periodontal disease, and dental caries and their sequelae were significant $(\mathrm{P}=0.000)$ relative to pericoronitis as reasons for the surgical extractions (table 2). Following treatment, the distribution of complications according to the types of impaction is shown in table 3.

Table (3):

Distribution of complications according to the types of impaction

\begin{tabular}{|c|c|c|c|c|c|c|}
\hline \multirow{2}{*}{ Complication } & \multicolumn{4}{|c|}{ Impaction } & \multicolumn{2}{c|}{ Total } \\
\cline { 2 - 7 } & DA & Vertical & Horizontal & MA & n & $\%$ \\
\hline Alveolar osteitis & 7 & 2 & 2 & 1 & 12 & 37.5 \\
\hline Hypersensitivity of adjacent molar & 3 & 4 & 0 & 3 & 10 & 31.2 \\
\hline Numbness of ipsilateral lower lip & $\mathbf{3}$ & $\mathbf{1}$ & $\mathbf{2}$ & $\mathbf{0}$ & $\mathbf{6}$ & $\mathbf{1 8 . 8}$ \\
\hline Mobility of adjacent $\mathbf{2}^{\text {nd }}$ molar & $\mathbf{3}$ & $\mathbf{0}$ & $\mathbf{1}$ & $\mathbf{0}$ & $\mathbf{4}$ & $\mathbf{1 2 . 5}$ \\
\hline Total & $\mathbf{1 6}$ & $\mathbf{7}$ & $\mathbf{5}$ & $\mathbf{4}$ & $\mathbf{3 2}$ & $\mathbf{1 0 0 . 0}$ \\
\hline
\end{tabular}

Alveolar osteitis and hypersensitivity of the adjacent molar were most common, 22 (68.7\%). The overall complication rate after treatment was 3.7\%. The complication rates were higher in disto-angular (48.5\%) and horizontal (26.3\%) impactions than in vertical (4.5\%) and mesio-angular (1.7\%). However, the complications associated with the surgical extraction of disto-angular impactions was significant relative to other types of impaction that were treated $(P=0.003)$. The complications were successfully managed during follow-up, and resolved without a permanent damage. 


\section{DISCUSSION}

This study showed low frequency of symptomatic malpositioned third molars in the oldest subjects. The most common reason for the extractions in this series was periodontal disease. This result is similar to the report of Moss et al., ${ }^{(10)}$ and Yamaoka et al., ${ }^{(11)}$ but contrary to some other reports ${ }^{(4,5,20)}$ that found dental caries and their sequelae, in addition to pericoronitis are the most significant reasons. Yamaoka et al., ${ }^{(11)}$ reported that impacted mandibular third molar extractions in elderly patients may be due to chronic pericoronitis that might have progressed to cause periodontal disease. Consequently, Hirota et al., (4) suggested that oral inflammation and infections in elderly patients are occasionally caused by retained impacted mandibular third molars with the overlapping of other confounding clinical factors that may be local or systemic. The age-related disease ${ }^{(22)}$ is due to the likelihood of bacterial accumulation and tissue inflammation with time which may be more pronounced in elderly patient. In addition, the anatomical position of the third molar most posterior in the mouth, which makes it more difficult to clean, contributes to the reported association of malpositioned mandibular third molars in the elderly patient with pathology. ${ }^{\left(10,{ }^{22}\right)}$ The pathological conditions that afflicted the malpositioned third molars in this study may be a direct consequence of the abnormal anatomical relationship between them and the adjacent second molar. ${ }^{(23,24)}$ This abnormal anatomical relationship creates stagnation area for accumulation of food debris, proliferation of harmful micro-organisms, formation of bacterial plaque, and because of the patients' inability to access that portion of the oral cavity properly during routine oral hygiene procedure result in disease by the time.

Mesio-angular impaction is the commonest types of impaction in this study which is in keeping with the findings of earlier researchers. ${ }^{(25,26,27)}$ The probability that impacted mandibular third molar will develop clinical symptoms in future in elderly remains unclear. However, some clinical features like the angulation, depth of impaction and patient's age could be useful in predicting the likelihood of development of symptoms. ${ }^{(28)}$

The frequency of symptomatic impactions obtained in this study is low but closely similar to that recorded by earlier researchers ${ }^{(4,5)}$ while on the other hand it is contrary to the result of Trybek et al., (29) who recorded a much higher frequency. The frequency is sometimes influenced by the study duration, type of study, population of the locality including the literacy level among other confounding variables that may determine the inclusion and exclusion criteria of patients for the particular study. The American Association of Oral and Maxillofacial Surgeons (AAOMS) consider third molars whether impacted or not, to pose a significant risk to the patients' well-being and therefore recommended extraction in adolescents and young adults in all cases including those are asymptomatic $(30,31)$ On the contrary, investigators in Canada stated that there is currently not enough evidence supporting or refuting the practice of prophylactic extraction of asymptomatic third molars, but advocates that each case should be treated on its merit. ${ }^{(32)}$ The frequency obtained in this study seems to justify the Canadian assertion.

This study showed that males were affected more than females, but the frequency of patients decreased as their age increased. From the authors' experience, this relative frequency may have been attributed to the attendance of males in the study center is more often than their female counterpart. However, the gender mostly affected is not conclusive in the literature as earlier studies have shown variation in this regard prompting researchers to suggest that it might be due to genetic inheritance in relation to the patients studied in a particular locality. ${ }^{(23,26,33)}$

The overall complication rate obtained in this study following treatment is within the range of $2.6 \%$ to $30.9 \%$ reported by earlier researchers. ${ }^{(5,16,29)} \mathrm{Age}$ of the patients, medical status, and integrity of adjacent structures during the surgical procedures may contribute to the complication rate obtained. Most researchers agree that patients over 60 years of age are more prone to risk of complications after surgery. ${ }^{(16,}$ 29) The age-related weakening of bony elasticity especially in the elderly patient makes extraction more difficult and prone to complication. ${ }^{(21)}$ The old persons could also be at a higher risk of complication possibly because of poor healing potential of their tissues, dense bones and completed dental roots. ${ }^{34,35 \text {, }}$ ${ }^{36}$ The most common complication in this study was alveolar osteitis which is similar to that of Chuang et al., (16) but it is contrary to the post-operative hematoma obtained by Trybek et al. ${ }^{(29)}$ The alveolar osteitis may have resulted from wound break down 
probably because of patients' and surgeons' factors and other local and systemic confounding variables that were not controlled due to the study was not prospective in design.

The hypersensitivity of the second molar was due to wound that exposed their roots. The break down may also be due to periodontal pocket that has been formed distal to the second molar after extraction of the impacted tooth and this cannot always be prevented especially when it is present preoperatively. ${ }^{\left(37,{ }^{38}\right)}$ The cases that presented resolved probably because the alveolar crest was preserved during surgery. Baqain et al., ${ }^{(37)}$ also noted that flap design had no influence on periodontal health postoperatively; hence this complication could not be caused by faulty incision during the surgical procedures.

The temporary numbness of the ipsilateral lower lip and mobility of the second molar could have been due to the inflammatory edema and cases where bone was mesially removed more extensively during the extraction. Similar reports have been documented by other researchers when in the case of numbness of the lower lip, was attributed to temporary inferior alveolar nerve paresis. $(16,24,38)$ The complication rate was lowest with the surgical extraction of mesio-angular impactions compared to disto-angular, horizontal, and vertical impactions probably because less amount of bone was removed during their extraction, which meant that their operations were not as extensive because of their lesser degree of impaction. Although the outcome of treatment can also be influenced by the competence of the operating surgeon among other confounding clinical and surgical factors $(9,20,39)$ not all the difficulty determinants are necessary prognostic factors for complication in the treatment of impacted mandibular third molar. ${ }^{(40)}$

Patients' false declaration of their ages by lowering it when they present in the hospital could have negatively affected the frequency of the impacted third molar. The practice of false declaration of age among patients is common in the study community. ${ }^{(41)}$ The medical history of the patients was not taken into account. Patients suffering from certain systemic diseases may have presented and this could have influenced the presence of symptoms associated with the impacted third molars, and also adversely affected the treatment outcome in some cases. The surgery of the impacted molars was done by different surgeons and the techniques of surgery were not uniform and standardized. This could introduce discrepancies that might have influenced the treatment outcome. It is also possible that some patients who had complications failed to report back to the hospital. These patients may have opted for alternative means of treatment or decided to live with their ailment.

\section{CONCLUSION}

This study showed low prevalence of symptomatic malpositioned mandibular third molars in the oldest subjects suggesting that majority of such impactions does not cause pathology even after many years of their presence in the oral cavity. Prophylactic extraction of such teeth in all patients should be discouraged, but each case should be treated on merit or when become symptomatic. Surgical removal of symptomatic malpositioned mandibular third molars is an effective treatment to maintain good patient oral health. However, the provision of cost-effective treatments during routine oral checks should be encouraged to reduce the burden of the impaction in elderly patients to the barest minimum. The outcome of this study should serve as a baseline investigation on which basis a prospective clinical study will be embarked upon to address the limitations of this retrospective study in this part of Nigeria.

\section{ACKNOLEDGEMENT}

The authors are grateful to Mrs. Adiaha Ofem of the Department of Health Records and Information Management of the institution for her assistance in making the patients' files available during data collection.

The authors have no conflict of interest to declare whether it is financial or personal relationships with individual(s) or organizations. The authors viewed, and consequently agreed to the submission.

\section{REFRENCES}

1. Huenchuan S, Rodríguez-PiñeroRoyo L. Ageing and the protection of human rights: current situation and outlook. United Nation Economic Commission for Latin America and Caribbean, Document UN. LC/W.35390, March, 2011.

2. United Nation Secretary General. Report on the follow-up to the Second World Assembly on Ageing, 9 3, UN. Document A/64/127, July 6, 2009.

3. Ahlqwist M, Gröngahl HD. Prevalence of impacted teeth and associated pathology in middle aged and older Swedish women. Community Dent Oral Epidemiol 1991; 19: 116-9.

4. Hirota J, Yoneda K. Infections in elderly patients associated with impacted third molars. Oral Surg Oral Med Oral PatholEndod 1995; 79: 137-141. 
5. Ventä I, Kyätie E, Hiltunen K. Pathology related to third molars in the elderly persons. Clin Oral Invest 2015; 19: 1785-9.

6. Von Wowern N, Nielson HO. The fate of impacted lower third molars after the age of 20: A four-year clinical follow-up. Int $\mathbf{J}$ Oral Maxillofac Surg 1989; 18: 277-280.

7. Anyanechi CE, Saheeb BD. The efficacy of tincture of benzoin compound in the management of extraction sockets of mesioangularly impacted mandibular third molar. Oral Surg 2013; 6: 137-141.

8. Msagati F, Simon EN, Owibingire S. Pattern of occurrence and treatment of impacted teeth at the Muhimbili National Hospital Dar es Salaam, Tanzania. BMC Oral Health 2013; 13: 37-42.

9. Susarla SM, Dodson TB. Risk factors for third molar extraction difficulty. J Oral Maxillofac Surg 2004; 62: 13631371.

10. Moss KL, Beck JD, Mauriello SM, Offenbacher S, White RP Jr. Third molar periodontology and caries in senior adults. J Oral Maxillofac Surg 2007; 65: 103-8.

11. Yamaoka M, Ono Y, Takahashi M, Ishizuka M, Uchihashi T, Yasuda $\mathrm{K}$, et al. Acute inflammation in horizontal incompletely impacted third molar with radiolucency in the elderly. Clin Interv Aging 2009; 4: 337-342.

12. Mizuno I, Mizutani H, Ueda M, Kaneda T. Temporal necrotizing infection of dental origin. J Oral Maxillofac Surg 1993; 51: 79-81.

13. Chiapasco M, Crescentini M, Romanoni G. Germectomy or delayed removal of mandibular impacted third molars: the relationship between age and incidence of complications. J Oral Maxillofac Surg 1995; 53: 418-422.

14. Ejim EC, Anisiuba BC, Oguanobi NI, Ubani-Ukoma BC, Nwaneli UC, Ugwu C, et al. Congenital heart diseases in adults: A review of echocardiogram records in Enugu, South-East Nigeria. Ann Med Health Sci Res 2014; 4: 522-5.

15. Joshi K, Kumar R, Avasthi A. Morbidity profile and its relationship with disability and psychological distress among elderly people in Northern India. Int J Epidemiol 2003; 32:978987.

16. Chuang SK, Perrott DH, Susarla SM, Dodson TB. Age as a risk factor for third molar surgery complications. J Oral Maxillofac Surg 2007; 65: 1685-1692.

17. Song F, Landes DP, Glenny AM, Sheldon TA. Prophylactic removal of impacted third molars: an assessment of published reviews. Br Dent J 1997; 182: 339-346.

18. Costa MG, Pazzini CA, Pantuzo MC, Jorge ML, Marques LS. Is there justification for the prophylactic extraction of third molars? A systematic review. Braz Oral Res 2013; 27: 183-8.

19. Friedman JW. The prophylactic extraction of third molars: a public health hazard. Am J Public Health 2007; 97: 1554-9.

20. Kandasamy S, Rinchuse DJ, Rinchuse DJ. The wisdom behind third molar extractions. Aust Dent J 2009; 54: 284-292.

21. Cankaya AB, Erdem MA, Cakarer S, Cifter M, Oral CK. Iatrogenic mandibular fracture associated with third molar removal. Int J Med Sci 2011; 8: 547-553.

22. Fisher EL, Moss KL, Offenbacher S, Beck JD, White RP Jr. Third molar caries experience in middle-aged and older Americans: a prevalence study. J Oral Maxillofac Surg 2010; 68:634-640.

23. Tsai HH. Factors associated with mandibular third molar eruption and impaction. J Clin Pediatr Dent 2005; 30: 109-113.
24. Saheeb BDO, Obuekwe ON. An audit of mandibular third molar surgery. Niger J Surg Res 2001; 3: 66-73.

25. Jaffar RO, Tin-Oo MM. Impacted mandibular third molars among patients attending Hospital UniversitiSains Malaysia. Arch Orofac Sci 2009; 4: 7-12.

26. Blondeau F, Daniel NG. Extraction of impacted mandibular third molars: postoperative complications and their risk factors. J Can Dent Assoc 2007; 73: 325-330.

27. Anyanechi CE, Saheeb BD. Nerve morbidity after mandibular third molar surgery: A prospective study of two cohorts of patients. J Neurol Neurosci 2015; 6: 43(1-5).

28. Fernandes MJ, Ogden GR, Pitts NB, Ogston SA, Ruta DA. Incidence of symptoms in previously symptom-free impacted lower third molars assessed in general dental practice. Br Dent $\mathrm{J}$ 2009; 207: E10.

29. Trybek G, Chruściel- Nogalska M, Machino M, SporniakTulak K. Surgical extraction of impacted teeth in elderly patients: A retrospective analysis of peri-operative complications- the experience of a single institution. Gerodontol 2015; 33: DOI: 10.1111/ger.12182.

30. Haug RH, Abdul-Majid J, Blakey GH, White RP. Evidencebased decision making: The

third molar. Dent Clin North Am 2009; 53: 77-96.

31. Blakey GH, Gelesko S, Marciani RD, Haug RH, Offenbacher $\mathrm{S}$, Philips C, et al. Third molars and periodontal pathology in American adolescents and young adults: a prevalence study. J Oral Maxillofac Surg 2010; 68: 325-9.

32. Canadian Agency for Drugs and Technologies in Health. Health Technology Inquiry

Service. Health Technology Assessment Prophylactic Removal of Wisdom Teeth: A

Review of the Clinical Benefit and Guidelines; 2010. p 1-15.

33. Stephens RG, Kogon SL, Reid JA. The unerupted or impacted third molars-a critical appraisal of its pathologic. J Can Dent Assoc 1989; 55: 201-7.

34. Bruce RA, Frederickson GC, Small GS. Age of patients and morbidity associated with mandibular third molar surgery. J Am Dent Assoc 1980; 101: 240-5.

35. Capuzzi P, Montebugnoli L, Vaccaro MA. Extraction of impacted third molars: A longitudinal prospective study on factors that affect post-operative recovery. Oral Surg Oral Med Oral Pathol 1994; 77: 341-3.

36. Bui CH, Seldin EB, Dodson TB. Types, frequencies and risk factors for complications after third molar extraction. J Oral Maxillofac Surg 2003; 61: 1379-1389.

37. Baqain ZH, Al-Shafii A, Hamdan AA, Sawair FA. Flap design and mandibular third molar surgery: a split mouth randomized clinical study. Int J Oral Maxillofac Surg 2012; 41: 1020-4.

38. Chiapasco M, De Cicco L, Marrone G. Side effects and complications associated with third molar surgery. Oral Surg Oral Med Oral Pathol 1993; 76: 412-420.

39. Sisk AL, Hammer WB, Shelton DW, Joy ED Jr. Complications following removal of impacted third molars: the role of experience of the surgeon. J Oral Maxillofac Surg 1986; 44: 855-9.

40. Carvalho RW, do Egito Vasconcelos BC. Assessment of factors associated with surgical difficulty during removal of 
impacted lower third molars. J Oral Maxillofac Surg 2011; 69: 2714-2721.

41. Anyanechi CE, Saheeb BD. Reasons underlying failure to seek early dental treatment among patients presenting in a Nigeria tertiary hospital. J Med Biomed Res 2013; 12: 37-45. 